97 BUILDING CAPACITY THROUGH A GRANTS PROGRAM. IS IT POSSIBLE?

${ }^{1}$ Venessa Wells, ${ }^{1}$ Rachel Meade, ${ }^{1}$ Emily Anderson, ${ }^{1} J u l i a n a$ Summers, ${ }^{2}$ Gemma Crawford, ${ }^{1}$ Ailsa Dinnes. ' 1 njury Control Council of WA, Western Australia; ${ }^{2}$ Curtin University, Western Australia

10.1136/injuryprev-2016-042156.97

Background The Injury Control Council of Western Australia (ICCWA) has delivered a grants program as part of the Stay On Your Feet falls prevention program since 2006. Historically grants were available to community groups and local government for projects that raise awareness of the Stay On Your Feet program, and increase access to falls prevention projects for the community.

Problem Research into the effectiveness and value of the grants program conducted in 2013 by Collaboration for Evidence, Research and Impact in Public Health (CERIPH) recommended an increased focus on supporting grants recipients to implement appropriate, evidence informed and sustainable projects.

Results In 2014 a revised pilot program was implemented as a strategy to build the capacity of health professionals in identifying and implementing effective falls prevention initiatives. Financial support is provided to deliver local falls prevention strategies. The program also incorporates free, non-compulsory coaching that aims to develop applicant's skills in; writing grants applications and reports, program planning, implementation, evaluation and partnerships.

Evaluation of the grants and coaching program explores the implementation and value of the approach. Preliminary results identify the program provides a valuable engagement opportunity when working with new stakeholders. Initial challenges included limited uptake of the coaching.

Conclusions The grants and coaching program supports innovative and local solutions to preventing falls in older adults. It recognises the diversity of needs and the vital role local services and community group's play in preventing falls. The pilot will run in five phases until 2017. This will enable program refinement and improve implementation. Future considerations include; whether the demand and outcomes of coaching merit the investment, additional resource requirements, and whether the experience gained by ICCWA will enrich support provided to the sector.

\section{PREVENTING FALL INJURIES WITH IMPACT ABSORBING FLOORING IN NURSING HOMES - A STUDY OF THE EFFECTS ON INJURIES AND WORK ENVIRONMENT}

Johanna Gustavsson. Karlstads University, Sweden

\subsection{6/injuryprev-2016-042156.98}

Background Fall injuries pose a global public health problem. Whilst all elderly are at risk of fall injuries, the risk of injury is 10 times as high amongst elderly living in nursing homes. An injury occurs when body tissue is subjected to external kinetic energy exceeding the tissue's tolerance. Reducing this energy in order to prevent injuries has been successfully applied in many fields. A impact absorbing floor as an energy reducing measure to prevent fall injuries has been evaluated. The aim of this study is to investigate the potential fall injury reducing effects of impact absorbing flooring in a nursing home, as well as the staff's experience of working in premises with impact absorbing flooring.

Methods The intervention site is a nursing home in Sweden where impact absorbing flooring was installed. To investigate the fall injury reducing effect falls on impact absorbing flooring were compared to falls on regular flooring. To describe how the staff presided working in premises with special flooring a qualitative focus group interview study were conducted.

Results The results show that for women the risk of injury following a fall on the impact absorbing flooring was 59\% less compared to falls on ordinary floors, after adjustment for age, BMI, vision impairments, and cognitive impairment. With regards to the staff's experience of the impact absorbing flooring, the nurses felt that the floor defused the falls and in that way reduced the risk of injury. They were also positively surprised by the change in acoustics. There were also some challenges associated with the floor, for example, adapting to walking on the floor and manoeuvring equipment (eg hoists).

Conclusions The results suggest that for an elderly and frail population, impact absorbing flooring seems to be an effective injury prevention measure. The intervention was generally perceived as positive by the staff, even though some negative aspects were observed. These aspects need to be studied further.

\section{A NEW SYSTEM FOR SHARING AND INFORMING SERIOUS INCIDENTS AMONG MULTIPLE NURSING FACILITIES}

1,2,3 Takeshi Dakeshita, 1,3,4 Koji Kitamura, 1,3,4 Yoshihumi Nishida, ${ }^{1,2}$ Horoshi Mizoguchi. ${ }^{1}$ National Institute of Advanced Industrial Science and Technology, Japan; ${ }^{2}$ Tokyo University of Science, Japan; ${ }^{3}$ RISTEX JST, Japan; ${ }^{4}$ Safe Kids Japan, Japan

\subsection{6/injuryprev-2016-042156.99}

Background Nursing facilities hold a big problem in preventing accidents including "slip" and "fall". To prevent injury, it is required to collect a large number of data and analyse causal factors $t$ related to injury, such as devices and environments, care worker's action, physical function and action of care receivers, and to share characteristics and patterns of injury in nursing facilities. But now it is difficult to collect and share injury data.

Methods In this study, we implement a new system with two functions using a latest cloud computing technology; i) A function to accumulate and search important injury data using a geographical-information-system-like software, and ii) a function to find and inform fatal or serious injury that facility staff should know by considering kinds of nursing tasks performed in the target facility. By applying the developed method into three nursing facilities, we confirmed the effectiveness of the system.

Results We collected 115 incident cases in total and input these incident data using the developed system; The system consists of a cloud server system and three client systems corresponding to three facilities. For example, using the system, staff could share not only statistics but also the concrete incident information as follows. By inputting a target moving route in order of "Cabin, Cafeteria, Water Closet, and Caregiver Station", the system find and inform a serious injury case occurred in the other facilities such as "a patient stood up and slipped before raising the underwear after elimination in the toilet."

Conclusions We verified that it was possible to share and inform important serious injury among nursing facilities. The advantages of the proposed cloud-computing-type system lie in 1) a large number of data can be collected by sharing the data among multiple facilities using the system even if the number of incident in a single facility is relatively small, and 2) facility staff can find important serious injury that might occur in the facility. 